\title{
I Have a Dream ...
}

\section{Mission ASI 2019-2021}

\section{Arvind Kumar ${ }^{1}$}

Published online: 19 March 2019

(C) Association of Surgeons of India 2019

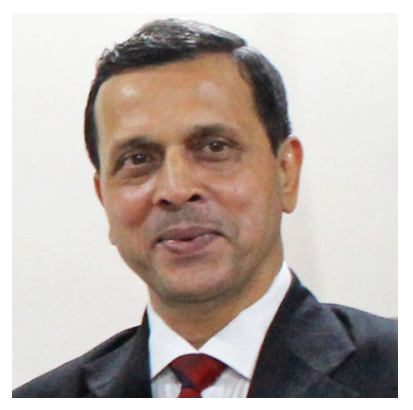

For years, I have been possessed by a dream to help members of our Association realise their "true potential" in their respective surgical specialities and make ASI, a vibrant, academic body. ASI has the potential to become the platform to standardise the training and skills development of young surgeons, raise the standard of Surgical Care across the country and ensure maintenance of proficiency. In today's era of general distrust towards the doctors, it is imperative that guidelines be formulated so that we all speak the same language. The only way to achieve these goals is through strengthening our Association of Surgeons of India.

As part of the leadership, we have a unique opportunity at our hands to help shape the future of ASI as a surgical body of repute at global level. With these goals in mind, we reached out to our member surgeons through their elected executive council members to suggest the areas of need, where ASI as a surgical association should work. Vast majority of the members responded and expressed the need to work on surgical resident training program, establishment of surgical guidelines

Arvind Kumar, President, ASI : 2019

Arvind Kumar

arvindreena@gmail.com

1 Centre for Chest Surgery, Sir Ganga Ram Hospital, New Delhi, India for various diseases and the need to work towards prevention of violence against doctors. The Executive Committee of ASI in its meeting on 30th December, 2018, in the presence of esteemed past Presidents Dr Santhosh J. Abraham, Dr Shiva K. Misra and Dr Dilip Gode and the President elect Dr Raghuram, discussed, approved and decided to launch 5 missions at national level, as detailed below:

Mission 1 Safe ASI: For Patients and Surgeons

Mission 2 Skilled ASI: For Surgeons and Residents

Mission 3 Digital ASI

Mission 4 Stronger ASI with "SAY" in decision making at national level

Mission 5 ASI responsive to medical social issues

These missions have been converted into "actionable projects", each of which is being piloted by one or more E.C. member as "project lead" for achieving results in a time bound manner.

I take this opportunity to share the missions and the various projects with our esteemed members to request them to own these projects and contribute to their success. Together, we can realise the dream of making ASI a body, which has presence and is counted at global level.

\section{Mission 1 Safe ASI for (A) Patients}

(B) Surgeons

\section{1 (A) Making Surgery Safe for Patients}

Most of us believe that we are saving lives through our surgeries. While it is largely true, we should also remember that medical error is one of the leading causes of death, even in developed nations with a robust error prevention and reporting system. A recent report reveals that in USA, medical error is the third leading cause of death. We on the other hand lag behind severely in this area and have no organised system of preventing or recording of morbidity and mortality due to treatment errors. It is high 
time that we address this issue and improve outcomes and reduce preventable deaths by making surgery safe for patients.

We have planned 5 projects under this part of Mission 1. These are as follows:

Project 1 Reduce Hospital Acquired infections (HAI)

Project 2 Reduce Complications in Surgery

Project 3 Reduce Medication Errors

Project 4 Reduce Antibiotic Misuse-Antibiotic Policy and Guidelines

Project 5 Enhance Patient Satisfaction

\section{1 (B) Making Surgery Safe for Surgeons}

While we strive to raise standard of care for our patients, we need to look after ourselves also and ensure safety of all our members. Projects planned under this part of Mission 1 are as follows:

Project 6 (A) Social Security Scheme: already rolled out at national level.

Project 6 (B) Professional Indemnity scheme: already rolled out at national level.

Project 6 (C) Support for Members at city / district / national level.

Project 7 Avoid Litigation and Violence: Popularise the 7 C Approach to patient care, i.e.

- Compassionate care,

- Attention to Communication,

- Attention to Consent,

- Proper recording in Case sheet,

- Proper Counselling: Under promise and over delivery,

- Check list based approach during surgery,

- No Criticism of colleagues.

Project 8 Prevent Patient to Doctor disease transmission (air borne and blood borne)

Project 9 NABH level Standardisation of facilities and/or accreditation of all units owned by ASI members across the country. ASI to act as facilitator, to do away with need for consultants.

\section{Mission 2 Skilled ASI for (A) Surgeons}

(B) Residents

\section{2 (A) Skilled ASI Enhancement of Surgical/Other Skills for Surgeons}

Project 10 Enhancing "Surgical Skills" of members
While we all keep upgrading our skills during the course of our career, spending time with a colleague in your state who has excelled in certain area, may provide the best opportunity to learn the finer nuances as well as build a long lasting bond. In order to achieve this goal, National Skill Enhancement Programme (NSEP) has been proposed with the aim to identify centres of excellence in various disciplines (breast, hernia, thyroid, GI surgery, thoracic, vascular etc.) which will be utilised as regional centres for training and skills enhancement of our members through an ASI coordinated application process. This will allow the necessary skills to reach the periphery.

Project 11 Enhancing "Other Skills" of Surgeon Members

- Communications skills (including patient counselling and handling media)

- Bedside manners, handling crowd, breaking bad news

- Academic skills:

- Research orientation

- Publications

- Presentations

- Data management: capturing, storage and management of data

- Video recording and editing

\section{2 (B) Skilled ASI Enhancement of Surgical/Other Skills for Residents}

Project 12 Standardisation of surgical training in various medical colleges/DNB centres across the country and development of exchange programs between different resource medical institutions for residents and faculty.

Project 13 Enhance the standard of surgical residency training

- Surgical skills training

- Basic and advanced surgical skills: to cover every system

- Anastomotic skills: basics of anastomosis, bowel, urinary, vascular

- Basic emergency procedures

- Basic laparoscopic skills

- BLS, ACLS, ATLS

- Basics of endoscopy

- Care of the critically ill surgical patient (in collaboration with RCS England)

- Communications skills (including patient counselling and handling media)

- Bedside manners, handling crowd, breaking the bad news

- Academic skills:

- Research exposure: community, ward and lab based

- Publications (compulsory publications during residency) 
- Presentation (compulsory presentation in state and national conferences during residency)

- Data management skills

- Capturing, storage and management of data

- Video recording and editing

- Annual theory and mock exams should be taken in every college

- Mandatory rural posting for 3 months during training in final year

Project 14 Counselling for Residents: Stress management/ Career Guidance facility

Project 15 Mentoring of Residents

- Mentoring of young surgeons under ASI recognised mentors

- Refresher courses for teachers for better training of residents

Project 16 Training/Skill enhancement of Paramedics in tier II and tier III cities for patient and surgeon safety

Project 17 ASI Guidelines in Surgery:

Initially, for ten common surgical emergencies: India specific national guidelines and later on for elective procedures also.

\section{Project 18 Regional Refresher Courses-PG Masterclass}

This exercise is already running with huge success for over 5 years now. We wish to improve it further by combining with skills workshops/video workshop/lectures in all the 5 zones: managed by ASI.

\section{Mission 3 Digital ASI}

Project 19 ASI website: make it more user friendly and useful to membership at large

We are living in a digital era, heading towards totally paperless future. We wish to incorporate this culture in our conferences as well as other activities. The website needs to become a strong medium of communication and information dissemination.

- Web-based master class, webinars and lectures at nonworking hours at least once a week

- App-based teaching and training modules

- Online master videos - free online access to members

- E-library for ASI members

- Medico-legal cases with verdicts and case discussions on website
- ASI training and teaching e-news once every 2-3 months

- FAQs/fliers for patients - downloadable from website by members

Project 20 ASI App, presence on digital media

Project 21 ASI Surgical Database: organ based

Project 22 Online Access to members for leading international surgical journals

\section{Mission 4 Stronger ASI with "SAY" in Decision Making at National Level}

\section{Project 23 ASI Membership}

- Update records of all existing e-registered ASI members

- Ensure e-registration of all unregistered ASI members

- Ensure those associate members who have passed MS to be updated to e-registered member's list

- Membership drive. Double the membership this year... All residents/Medical college faculty to be made members, Existing members... Each one to get one...

Project 24 ASI Legal Cell to help colleagues in distress/ Protect-our colleagues who are facing legal issues-legal help

Project 25 ASI Rural Cell to develop surgical help in rural India, surgical camps in every state with minimum expenditure, and maximum benefit to the society

Project 26 Changes in ASICON and State Chapter meetings

- Stop live workshops at ASICONs, virtual live workshop (unedited or partly edited videos with national/state representation).

- State chapter conferences also to phase out live workshops gradually in tune with the MCI requirements.

- Uniform pattern and level of all state chapter conferences

- WHO patient safety challenges to be repeated across the conferences. (mandatory ASI module in every state chapter conference)

- Mandatory PG teaching session in every conference

- Shorter and crisper conferences, More: How to do and Guidelines based

- Scientists/academicians to be invited as chief guests

- No bouquets, shields, bags, malas, angavastram, shawls etc

- Give surgical books or motivational books as mementoes: encourage reading habits

- Paperless, plastic free, environment- friendly conferences

- Focus on academics with minimum pomp and show.

- Accounting to be made transparent and as per guidelines.

- Need to send out a clear message and publicise it. 
Project 27 Image Enhancement

- Sensitising members about ethical surgical practice

- Incorporation of ASI's VAPI Consensus Statement on "ethical surgical practice".

- Various social welfare schemes of ASI to be highlighted in media and public by members as well as leadership

- Welfare work done by individual members also to be projected across various states and at national level

- All members in various states to write regularly in leading newspapers about success and pitfalls of surgery.

- Adequate use of audio and visual media to highlight good work done by members

- ASI leadership to address and interact with media frequently for image building.

- Strict control over ASICON as well as State Chapter meetings to avoid pomp and show/negative publicity and highlight the academic achievements of members.

Project 28 ASI to have "SAY" in various issues at National Level

- ASI leadership should be involved in decision making at National Medical Commission (erstwhile MCI) and government level on matters that affect surgeons

- Explore the avenues to have "capping" of penalty money in consumer court cases.

- Recognition of surgeons as healthcare providers by government and insurance companies, fees to be based on a formula and transfer of money in a fixed time frame.

- ASI should have a say in fixing of "surgeon fee" in various schemes by insurance companies, TPAs, health care providers, state governments and government of India (Ayushman Bharat scheme)

\section{Mission 5 ASI Responsive to Medical Social Issues}

While we all continue to do surgical work, our medical social responsibility also needs to be fulfilled and announced to the world loud and clear. We have proposed following projects under this mission:

\section{Project 29 Rural Surgical Camps}

- Make maximum use of local resources including operating surgeons as there will be enough local talent available and would reduce the cost.

- Simple working breakfast and meals.

- Preferably more open surgical work and if needed laparoscopic work also.
- No banquet/fellowship during such programs as it takes away the impression what you are trying to create in the local mindset of people and media. We do not want them to make "Surgeons are having fun" kind of remarks.

- No other luxurious spending.

Project 30 Disaster Preparedness

Project 31 Doctors for Clean Air

- Advocacy for clean air: create public outrage against deteriorating air quality which is causing havoc to our health.

Project 32 Adopt a Village

- Encourage ASI members to adopt a village each and work for upliftment of the population.

- ASI district/state chapters to coordinate and report to headquarter for presenting it at the national level.

Project 33 Public awareness campaigns

- ASI to conduct nationwide awareness campaign on important issues like cancer, obesity, increasing incidence of road traffic accidents and against smoking and chewing tobacco use.

Each of these projects have been assigned to a "project lead" who will prepare the awareness document, share it with members, encourage and ensure compliance in a time bound manner and evaluate and document post intervention improvement.

Setting highest quality standards as a surgeon is our duty and an obligation. Above-mentioned missions and projects are designed to be steps in that direction. While we will strive to roll them out as early as possible, it is obvious that it will take time to see their effects in a vast country like ours. What is more important is to first acknowledge the need for driving such a change and then start taking the steps to ensure achievement of our targets. All these endeavours are directed to safe care which will lead to better outcomes which in turn will help thousands if not millions of lives.

I take this opportunity to present this mission document through our prestigious Indian Journal of Surgery. I implore upon our esteemed members and most humbly request each one of you to join hands in this endeavour and help realise the long-cherished goal of taking ASI to a global level.

Long Live ASI!

\section{"Alone we can do so little, Together we can do so much" Helen Keller}

Publisher's Note Springer Nature remains neutral with regard to jurisdictional claims in published maps and institutional affiliations. 